\title{
Methodology Proposed for Estimating Biowaste Generation Using Municipal Rurality Indexes
}

\author{
M. Baquero ${ }^{1} \cdot$ E. Cifrian ${ }^{1}$ (I) $\cdot$ L. Pérez-Gandarillas ${ }^{1} \cdot$ A. Andrés ${ }^{1}$
}

Received: 2 December 2020 / Accepted: 20 August 2021 / Published online: 7 September 2021

(c) The Author(s) 2021

\begin{abstract}
The separated collection and management of biowaste (BW) must be implemented in next years in the European countries. In order to define a proper BW strategy, it is necessary to estimate the generation at a municipal level, since depending on the amount to be treated, the strategy may notably vary. The aim of this study is to develop a methodology to estimate BW generation at municipal level taking into account the characteristics of the region, the Municipal Solid Waste management applied, and different socio-economic variables that define the level of rurality of a municipality. A model to estimate the BW generation for each type of municipality has been developed using Multiple Linear Regression Analysis. As input data, results from a Waste Compositional Analysis executed by the regional government to samples collected on 38 municipalities and data related to influential socio-economic variables have been used. Significant influence of socio-economic variables on BW generation is observed for the rural municipalities. The evolution of these characteristics, as well as the greater awareness of society with food waste, have change the consumption patterns. Therefore, it is not recommended to use static ratios, but models that allow including socio-economic changes in the estimation of waste generation.
\end{abstract}

\section{Graphic Abstract}

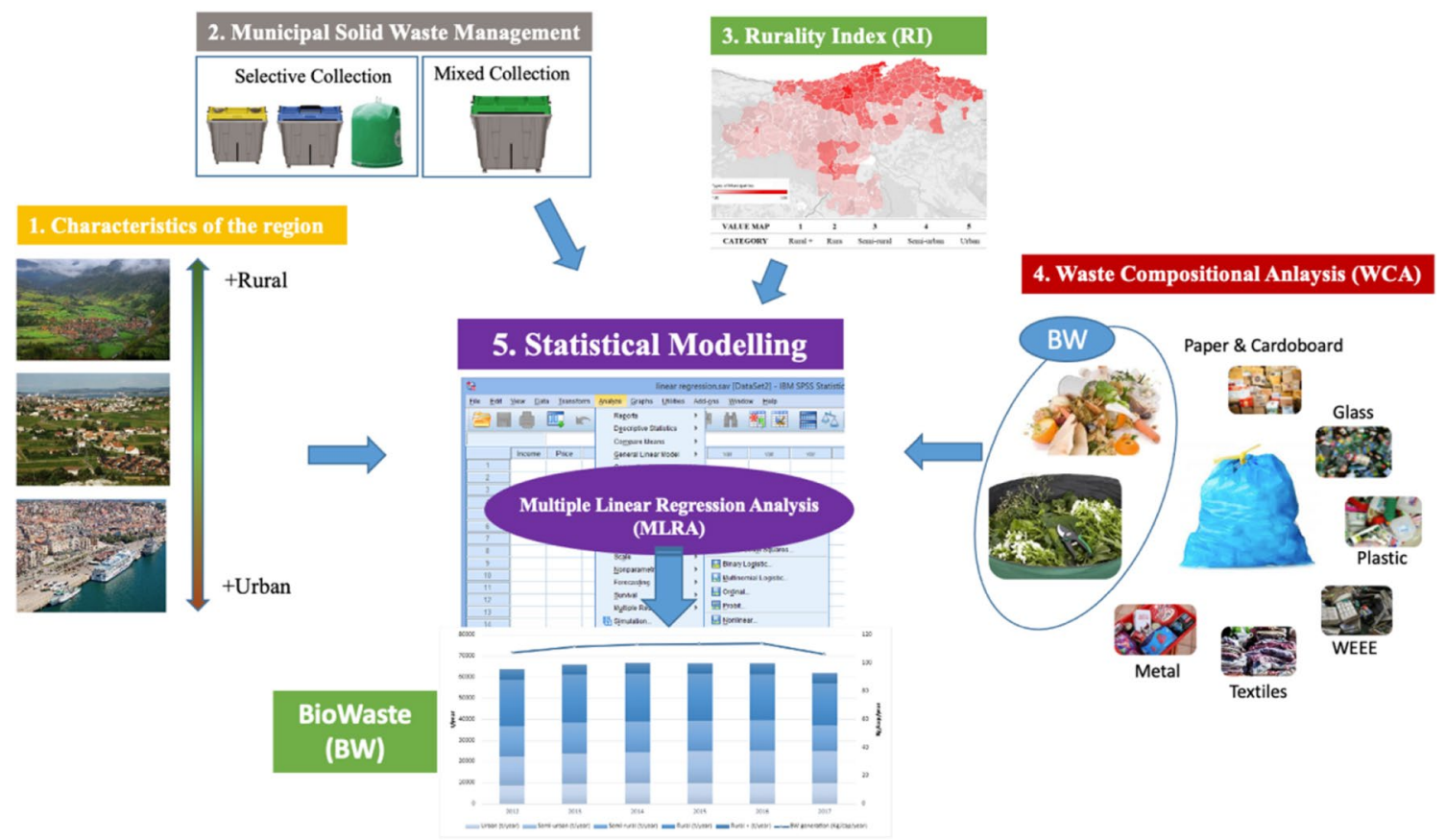

Keywords Biowaste $\cdot$ Estimation $\cdot$ Rurality $\cdot$ Regression analysis

Extended author information available on the last page of the article 


$\begin{array}{ll}\text { Abbreviations } \\ \text { ANN } & \text { Artificial neural networks } \\ \text { ARIMA } & \text { Autoregressive integrated moving average } \\ \text { BW } & \text { Biowaste } \\ \text { EU } & \text { European union } \\ \text { FW } & \text { Food waste } \\ \text { JN } & \text { Junior index } \\ \text { MLRA } & \text { Multiple linear regression analysis } \\ \text { MSW } & \text { Municipal solid waste } \\ \text { PD } & \text { Population density } \\ \text { RI } & \text { Retirement index } \\ \text { S1 } & \text { Primary sector working index } \\ \text { S2 } & \text { People working in the industry } \\ \text { S3 } & \text { People working in the services sector } \\ \text { SN } & \text { Senior index } \\ \text { VIF } & \text { Variance influence factor } \\ \text { WCA } & \text { Waste compositional analysis }\end{array}$

\section{Statement of Novelty}

The novelty of this study lies with the development of a methodology to estimate BW generation at municipal level, considering the characteristics of the region, the Municipal Solid Waste (MSW) management applied, and different socio-economic variables that define the level of rurality of a municipality. A model to estimate the BW generation for each type of municipality has been developed using Multiple Linear Regression Analysis.

\section{Introduction}

According to the Directive 2008/98/EC of the European Parliament and of the Council of 19 November 2008 on waste [1], Biowaste (BW) is defined as "biodegradable garden and park waste, food and kitchen waste from households, offices, restaurants, caterers and retail premises and comparable waste from food processing plants". Even though this Directive has been modified by the Directive (EU) 2018/851 of the European Parliament and of the Council of 30 May 2018, which amends the Directive 2008/98/EC on waste [2], the definition of BW has remained untouched. This waste flux is formed by (i) food waste (FW) formed by edible and inedible fractions of food, (ii) small vegetal fractions derived from gardening and pruning, and (iii) bigger pruning waste $[3,4]$. While small vegetal fractions are generally generated in households, bigger pruning waste are generated in residential areas, gardens and parks. Furthermore, FW can be generated during (i) food production, (ii) manufacturing, (iii) retail and (iv) consumption in the services sector and in households [5]. However, the FW that is included in the BW definition established in the European Directives, excludes the waste generated during production.

The Directive 2018/851 [2] incorporates important modifications in relation to $\mathrm{BW}$ collection and management for all Member States:

- By 31 December 2023, BW must be collected separately, or separate and recycled at source, but never mixed with other types of waste.

- From 1 January 2027, BW entering aerobic or anaerobic treatment will be count as recycled, only if it has been separately collected or separated at source.

- As a consequence, home composting must be encouraged.

Due to these modifications, significative changes must be made to the Municipal Solid Waste (MSW) collection system. Till now, a high proportion of BW (FW and small vegetal fractions) has been collected mixed with other types of MSW (paper, glass, metals, wood, cloths, etc....). However, the implementation of a new collecting bin, and the encouragement of home composting must be executed before 31 December 2023.

It is necessary to estimate the BW generated to stablish a proper new collection and management scheme. The main difficulty lies with the fact that small vegetal fractions and FW are still collected in many regions mixed with other types of waste. Thus, establishing the estimation method is a critical step in the decision-making process.

The BW generation and therefore the management strategy that must be developed in next years will be closely related with the type of municipality, urban or rural, so first it is needed to define the typology of the municipalities. Depending on the characteristics of each region and municipality, the chosen collecting system for each of them will notably vary [6]. The rurality index is a helpful tool that can help the decision-makers to include this in the decisionmaking process.

\section{Rurality Index}

Currently, there is an open debate about what being "rural" means, so a definition of this concept is needed in order to optimize resource allocation and ease decision making [7]. Therefore, there is no standardized methodology that can be used to obtain a rurality index for a region, neither the variables associated to this concept. Population density has been traditionally used as an indicator to distinguish between (i) urban, (ii) intermediate and (iii) rural areas [8,9]. This has been used by the OECD [10], who established in 1961 this criterion to consider as rural any area whose population density is lower than 100 inhabitants per $\mathrm{Km}^{2}$. 
At a national level, in Spain, The White Book of Agriculture and Rural Development [11] classifies the areas that form the regions into (i) mainly rural, (ii) rural, (iii) semirural and (iv) urban, depending on the population density and the intensity of agriculture and livestock. In addition, Prieto-Lara and Ocaña-Riola [7], López-Ratón and Santiago [12] and Ocaña-Riola and Sánchez-Cantalejo [13] executed studies in which a specific rurality index was developed for a specific region, considering demographic, economic and environmental variables.

These studies do not include in their definitions of rurality all the variables that are related to the generation of BW, so a new rurality index, adapted to the characteristics sought, must be developed.

\section{Biowaste Estimation Methods}

For each type of municipality, it will be necessary to make an estimation of the amount of BW generated and for that, the most appropriate estimation method must be selected.

The variety of methods used to estimate BW generation is wide. Xue et al. [14], classify these methods into two categories: (i) direct methods based on first-hand data, and (ii) indirect methods derived from secondary data.

One of the most frequently used direct method is the Waste Compositional Analysis (WCA).WCA is commonly used to determine the composition of waste streams collected by local authorities [15]. An example of this method is the characterisation of the FW generated by households, taking data from the collecting bins by those who will execute the quantification [16].

Among the indirect methods, using existing data (as ratios) and modelling are widely applied. Using existing data is the easiest, cheapest and quickest among all methods. These ratios are obtained from another case studies, databases or statistics. However, its accuracy depends on the reliability of the source of data [14]. This is related to its main drawback, which is that the data used to execute the estimations might be very different, depending on how it was initially obtained.

Mathematical, statistical or computational modelling is used to calculate BW generation quite efficiently. Its main advantage is that they allow the inclusion of climatic phenomena, agricultural statistics or other variables with influence, for example, on the different Food Supply Chain Stages [17], as well as the characteristics of the region or municipality in which the study is being executed.

Different models have been used to estimate and predict MSW generation, such as Multiple Linear Regression Analysis (MLRA), Artificial Neural Networks (ANN) or Autoregressive Integrated Moving Average (ARIMA) [18]. A combination of MLRA and ANN has been used by Azadi and Karimi-Jashni [19] to predict MSW generation, obtaining that ANN is more precise to make this prediction than the MLRA, although it requires a high amount of data that are not always available, especially if these data correspond to variables at a local level. In addition, to use ANN a deep knowledge of the tool is needed due to its complexity. MLRA is a quite simple statistical method that allows estimating BW, but not requiring that amount of data, and considers paramount socio-economic variables of each municipality [20].

The ARIMA model, has result be the most appropriate model to forecast MSW generation [21, 22]. One of the main characteristics of this method, is that to be used, the evolution of the temporal series must be similar to the one had in the past [23].

The aim of this study is to develop a methodology to estimate the BW generation at municipal level, taking into account (i) the characteristics of the region, (ii) the MSW management applied, and (iii) different socio-economic variables that define the level of rurality of a municipality. A model to estimate the BW generation for each type of municipality has been developed using MLRA based on the results of a WCA executed over 38 municipalities.

\section{Methodology}

In the Fig. 1 the methodology developed to estimate the BW generation is shown.

As shown in the Fig. 1, the methodology includes five main steps: (i) Identification of socio-economic variables of the region of Cantabria that have influence on the rurality of the municipalities and on waste generation, (ii) Collection of information and MSW generation data in Cantabria, (iii) Development of a Rurality Index to classify the municipalities of Cantabria, (iv) Collection of the data obtained by the Waste Compositional Analysis and combination with the MSW generation data, and (v) development of the statistical model to estimate BW generation at a municipal level.

\section{Characteristics of the Region}

Cantabria is a small region of $5300 \mathrm{Km}^{2}$ located in the north of Spain, and it is formed by 102 municipalities that are distributed in three major areas: the coast, the centre and the south. According to the regional statistics office, 582,206 people lived in this region during 2016 [24]. However, a high proportion of its population is concentrated in the coastal area, where the two main urban areas (Santander and Torrelavega) are located [25]. In addition, during summer, these coastal areas receive people from other Spanish regions who have a second house in Cantabria, so population in these municipalities significantly grows. According to estimations executed by local governments, 


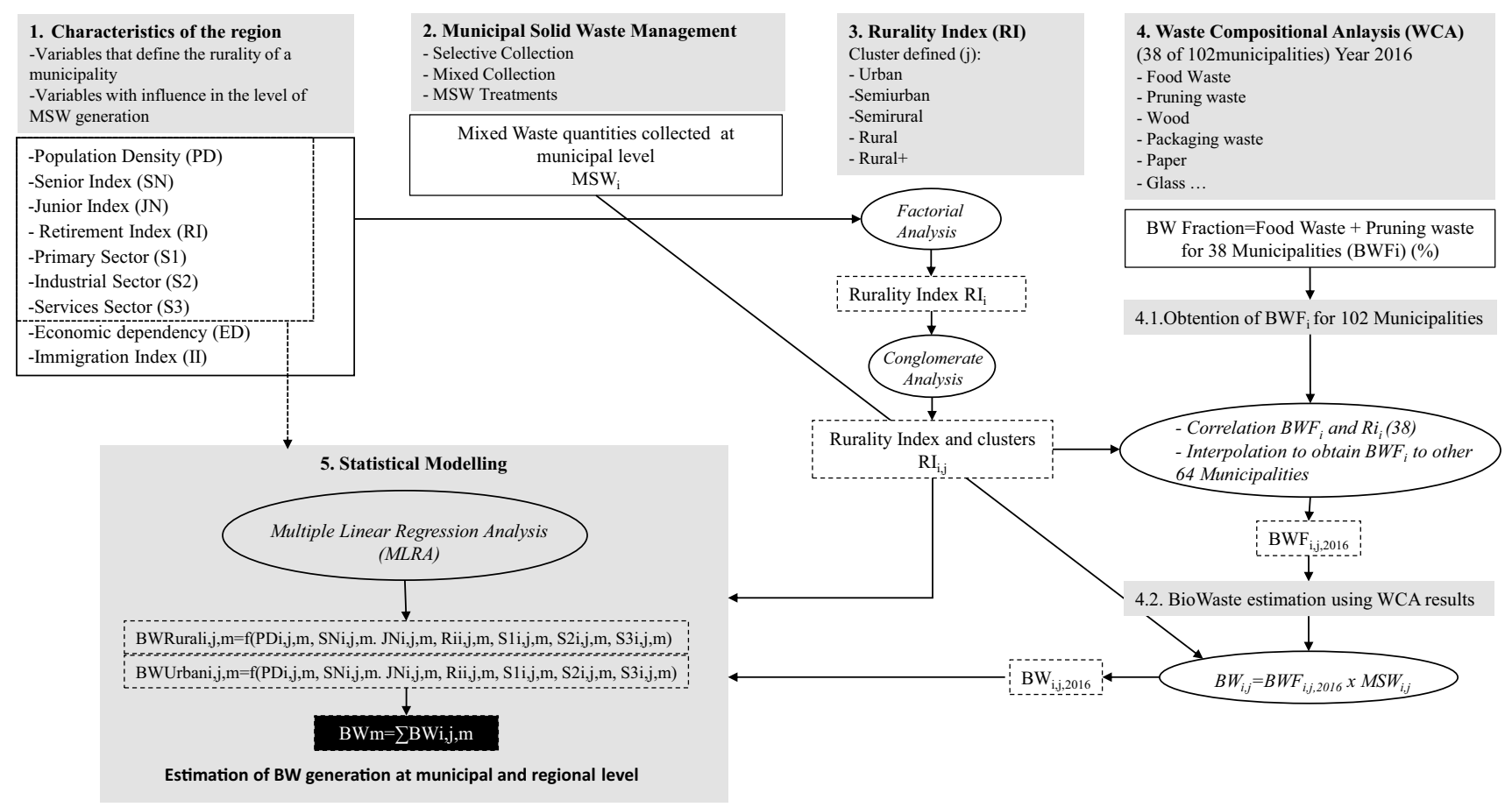

MSW: Municipal Solid Waste mixed collection; RI: Rurality Index; WCA: Waste Compositional Analysis; BWF: Biowaste Fraction; BW: Biowaste estimation; Subscripts indicate: i:municipality; j:rurality cluster; $m=$ year

Fig. 1 Methodology developed to estimate the BW generation at a municipal level

in some of these municipalities the population increases 30 times during summer [26]. This means that population in Cantabria is not homogeneously distributed: while the municipalities located in the coastal areas have a high population density, those in the centre and south have a notably lower population density.

In coastal areas, the most developed activities are related to the services sector, representing the $70 \%$ of the regional production, and industry, which represents the $22 \%$ of the regional production. On the other hand, in the centre and south of Cantabria, population are dedicated to agriculture and livestock, which represents the $1-2 \%$ of the regional production [25]. This entails that younger people and immigrants tend to live in municipalities located in the coastal areas, where job opportunities are more numerous and related to industry and services.

As it has been mentioned, the municipalities, due to the area in which they are located, have very different sociodemographic and economic characteristics that define them, such as (i) population density, (ii) ageing rate, (iii) youth rate, (iv) immigration index, (v) people working in primary (vi) industry and (vii) services sector.

\section{MSW Management}

According to the Spanish law 22/2011, of wastes and contaminated soils [27], local entities must provide the collecting, transport and management of the MSW generated in households and stores.

In Cantabria, MSW is collected using four kerbside bins: (i) a grey bin for mixed MSW, (ii) a yellow bin for plastic and metal packaging, (iii) a blue bin for cardboard packaging and paper, and (iv) a green bin for glass packaging. Vegetal oils and clothing are also collected in different kerbside bins that are located, in a lower proportion, in specific areas of the municipalities. In addition, there is also a network of green points where specific wastes can be left to ease their selective collection (e.g., furniture, bulky waste, electronic devices or electrical household appliances).

Currently, the biodegradable fraction of the MSW (excluding bigger pruning waste), which is formed by $\mathrm{FW}$ and small vegetal fractions, is collected in the grey bin mixed with other waste materials that were not deposited in a selective collection bin by citizens. These mixed MSW are transported and managed in a central MSW facility 
(Meruelo) where the BW is separated from the other MSW materials using a trommel, and then composted. The rejections produced after the composting process are incinerated to produce energy [28]. However, according to the Directive 2018/851 of the European Parliament [2], this collection and management strategy will no longer be adequate, so a new one must be defined.

\section{Rurality Index}

The socio-economic characteristics of the municipalities of Cantabria will have a strong influence on the future BW management strategy. In order to simplify the assessment of this influence, the 102 municipalities of the region have been classified into five categories depending on their rurality degree: (i) Urban, (ii) Semi-Urban, (iii) SemiRural, (iv) Rural and (v) Rural ${ }^{+}$.

To do the classification a rurality index has been developed, considering the independent socio-economic variables that reflect the level of rurality of a municipality. Variables related to the three dimensions of sustainability (Environment, Society and Economy) should be considered, to obtain an index as complete as possible.

In this study, some of the variables suggested by PrietoLara and Ocaña-Riola [7], López-Ratón and Santiago [12], Quintá and Arce [29] and Lasarte-López et al. [30], have been considered, taking into account the data availability for Cantabria: (i) Population Density (PD, hab/ $\mathrm{Km}^{2}$ ); (ii) Senior Index (SN, \%); (iii) Junior Index (JN, \%); (iv) Primary Sector Working Index (S1, \%); (v) Industry Working Index (S2, \%); (vi) Immigration Index (IM, \%); (vii) Economic Dependency Index (ED, \%); and (viii) Retirement Index (RI, \%). The necessary data to calculate these variables for each municipality have been obtained from the regional statistics office [24].

Before the analysis execution, it is necessary to ensure that (i) the variables are continuous, (ii) the sample size is large enough, and (iii) the variables follow a normal distribution [31]. The statistical method applied was the Factorial Analysis [7, 12], which delivers a linear function as a result that relates the independent variables, weighting the influence of each one. To obtain these weights, the Principal Component Analysis was used, whose objective is to gather the information of a specific number of variables into a lower number of components or factors, orthogonal among each other [12]. Once these factors are extracted, the rotation of their values is executed using the Varimax rotation and the Kaiser normalization. Then, the final weights and the linear function that provide the rurality index are obtained.

The results obtained were standardised, using the Eq. 1, so their values will vary between 0 and 1 :
$R I_{\text {standard }}=\frac{\left(R I_{i}-R I_{\min }\right)}{\left(R I_{\max }-R I_{\min }\right)}$

To classify the 102 rurality indexes into the 5 categories that have been established, a Conglomerate Analysis is executed and using the Ward method.

All statistical analysis has been executed using SPSS (IBM) Software.

\section{Biowaste Estimation}

The collection companies provide data related to MSW collection (grey bin) in each of the 102 municipalities of Cantabria. It is necessary to define the ratio of BW composition in MSW for each municipality and its evolution over time.

Periodically, the regional Ministry of Environment develops and updates the Waste Plan of Cantabria, in which the current outlook of waste in the region is presented. In that section, a global characterisation of the MSW generated in the region is provided. The percentage of BW collected in the grey bin provided by the Waste Plan [28] has been used to estimate $\mathrm{BW}$ in the region for years. However, this ratio has been obtained from a single compositional analysis of municipal waste from the whole region, so its use to estimate BW at the municipal level entails a significant error.

In this study, a new methodology is proposed to estimate the BW generation at municipal level, modelling different socio-economic variables that in different studies have shown an impact on the generation of BW and that can be obtained at the municipal level. Two aspects of the methodology must be highlighted: (i) In order to apply the modelling to the socio-economic variables it is necessary to have a complete characterisation of the waste generated in the different municipalities; (ii) Once the modelling has been carried out, it can be used to estimate the BW of each municipality using the socio-economic variables of each year, without the need to carry out further characterisations or wait for the collection data from the companies involved.

In Table 1 the characteristics of the estimation methods considered, existing data, previously applied, Waste compositional analysis to characterise at municipal level the MSW composition and the modelling developed in this study, are collected.

\section{Waste Compositional Analysis}

Data from the characterisation of the waste generated in different municipalities have been obtained. The analysis of 26 samples of the MSW (collected during July and August 2016) from different municipalities and transfer stations was executed. This characterisation determined the percentage of each waste material in the sample: (i) FW, (ii) small vegetal fractions, (iii) wood, (iv) packaging waste, (v) paper, 


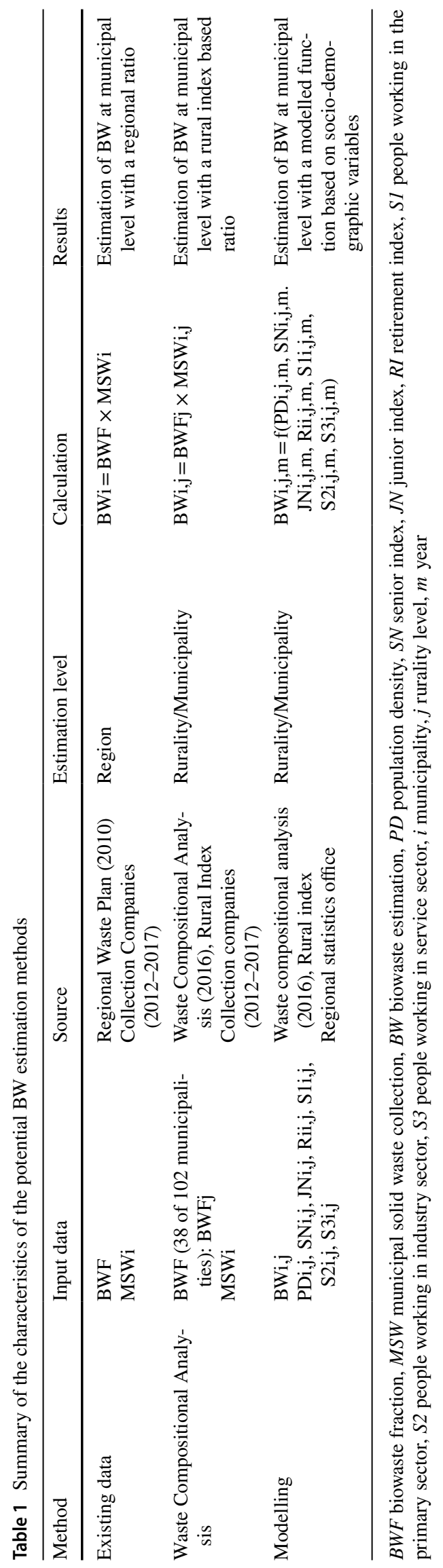


(vi) glass, (vii) clothes, (viii) metals, (ix) plastics and (x) hazardous waste. As a result, with the 26 samples, the waste from 38 municipalities have been characterised (considering the transfer stations). This characterisation does not provide information of the 102 municipalities, so, for those municipalities whose percentage of BW is not provided, the percentage of BW of another municipality with the same or similar Rurality Index has been ascribed.

\section{Statistical Modelling}

Considering the availability, characteristics, quantity of data, and the purpose of the study, the chosen model to estimate BW generation in Cantabria was the MLRA since this method is accurate enough to make the estimation with small economic and time-consuming costs. Data from the Waste Compositional Analysis and a number of socio-economic variables that have influence on BW generation have been used. MLRA provides a tool that allows to estimate the generation of biodegradable waste, regardless of whether the socio-economic situation changes over time.

Given that the number of municipalities is not high enough to develop one equation per category, only two MLRA have been developed: one for rural municipalities (including municipalities defined as Rural +, Rural and Semi-rural), and another one for urban municipalities (including Urban and Semi-Urban).

In order to obtain a linear relation between the independent and dependent variables, some of them need to be transformed into their logarithmic form. The potential co-linearity problems among the independent variables are identified analysing the coefficients related to colinearity among variables: Tolerance and the Variance Influence Factor (VIF). The chosen method to introduce the variables into the equations is the INTRO method, which includes all the considered variables in the analyses.

\section{Results}

\section{Rurality Index}

In order to obtain a rurality index taken into account the socio-economic characteristics selected, a Factorial Analysis has been executed. As a result, the software SPSS provides the rotated component matrix (Table 2), in which the considered variables, as well as their lineal relation are presented.

Two different components have been defined. According to the values collected in the rotated component matrix, the rurality index of each municipality is a lineal combination of the variables selected as influential in the Factorial Analysis:
Table 2 Rotated component matrix

\begin{tabular}{llc}
\hline Socio-economic variables & \multicolumn{2}{l}{ Component } \\
\cline { 2 - 3 } & 1 & 2 \\
\hline Senior index & -0.914 & - \\
Junior index & 0.900 & - \\
Population density & 0.887 & - \\
People working in agricultureand livestock & -0.866 & - \\
Retirement index & -0.736 & - \\
Immigration index & - & - \\
Economic dependency index & - & - \\
People working in the industry & - & 0.882 \\
\hline
\end{tabular}

$R I_{i}=0.9_{J N_{i}}+0.887_{P D_{i}}+0.882_{S 2_{i}}-0.736_{R I_{i}}-0.866_{S 1_{i}}-0.914_{S N_{i}}$

The immigration index and the economic dependency index are not influential enough in the rurality of Cantabria to be included in the index definition. On the other hand, junior index, population density and people working in the industry have positive influence on the rurality index; while the senior index, retirement index and people working in the agriculture and livestock sector have negative influence. These are the variables that are usually associated to rural areas: aged population that are highly dependent on agriculture and livestock activities. This entails that, the lower the rurality index is, the more rural the area is and vice versa.

Using Eq. 2, the rural index of the 100 municipalities that are not defined as urban in Cantabria, have been calculated. To categorise these 100 municipalities, a Conglomerate Analysis has been executed, using the rurality indexes calculated with Eq. 2 and having fixed four clusters: semi-urban, semi-rural, rural and rural ${ }^{+}$. The characteristics of these four types of municipalities are shown in Fig. 2.

As a result, the SPSS software provided the classification of the 100 municipalities into the four categories that correspond to the fixed clusters. These results are associated to the map of Cantabria, in which the 102 municipalities are represented, in Fig. 3.

As it is shown in Fig. 3, Cantabria is mainly rural, given that the vast majority of the region, the $97 \%$ of the total area, is semi-rural, rural or rural ${ }^{+}$, while only the $3 \%$ is urban or semi-urban. On contrast, $56 \%$ of the population lives in urban and semi-urban areas, while the $44 \%$ is located in rural areas. Rural ${ }^{+}$municipalities are especially unpopulated areas, provided that they span the $64 \%$ of the total area of Cantabria but only the $6 \%$ of the population lives there.

\section{Waste Compositional Analysis}

The percentage of BW in the grey bin (FW and small vegetal fractions) obtained through this method varies between the 


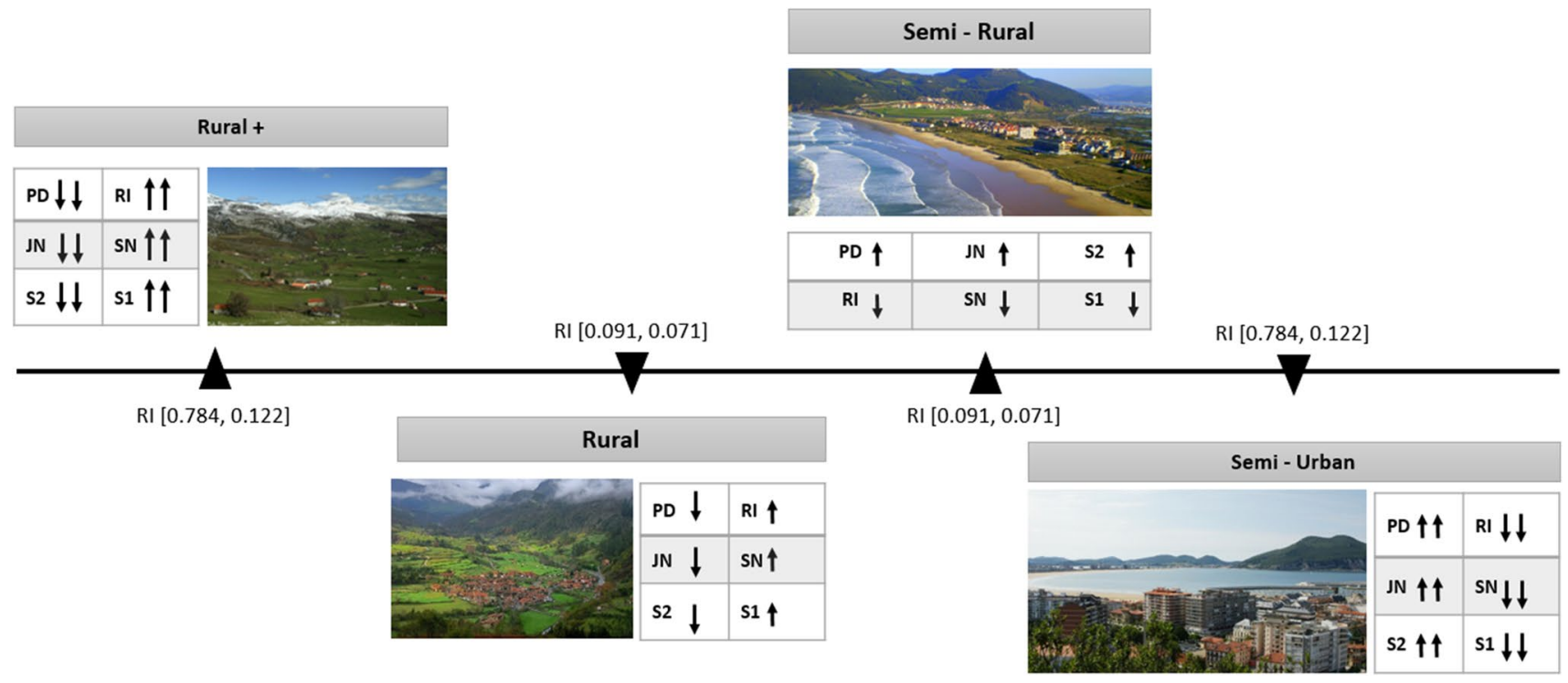

Fig. 2 Characteristics of the different types of municipalities

Fig. 3 Classification of the municipalities of cantabria depending on their rurality index

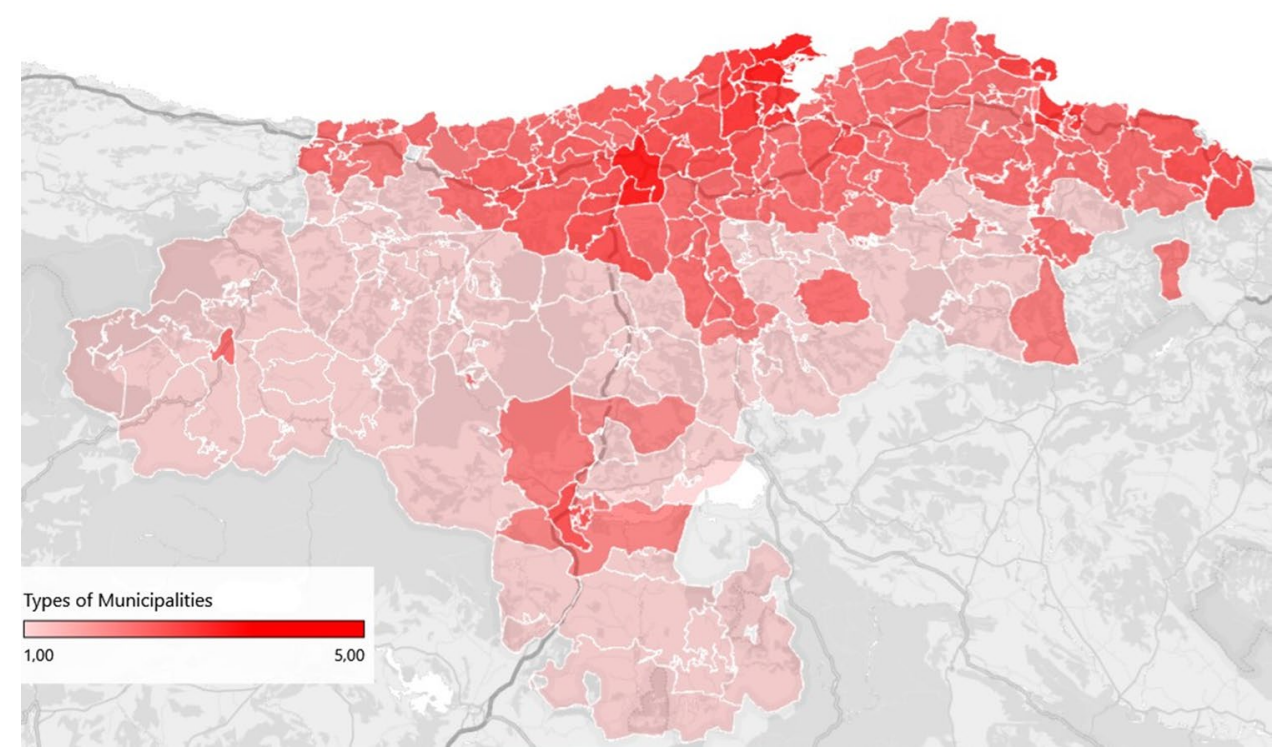

Table 3 Percentage of biowaste on the MSW of each type of municipalities

\begin{tabular}{llll}
\hline & Max & Min & Mean \\
\hline Urban & 56 & 19 & 37 \\
Semi-Urban & 53 & 24 & 37 \\
Semi-Rural & 47 & 25 & 33 \\
Rural & 47 & 24 & 33 \\
Rural + & 37 & 24 & 31 \\
\hline
\end{tabular}

$19 \%$ and the $68 \%$. In general, the results obtained show that the highest percentages of BW in the grey bin (38-56\%) correspond to urban, semi-urban and semi-rural municipalities, while the lowest ones $(<35 \%)$ correspond to rural and rural $^{+}$municipalities. The maximum, minimum and mean values are presented in Table 3 . These values coincide with the percentages provided by the Spanish Ministry of Agriculture and Environment [32]: at a national level the average percentage of BW in the grey bin in Spain is $44 \%$, while the values in the Spanish regions varies between 30 and $65 \%$.

However, there are some outliers in the results that need to be deeply studied. On the one hand, the municipalities with the highest percentages of BW were rural (6) and semirural (1) municipalities in which a high proportion of small vegetal fractions are thrown away (60\% of the total MSW generated). However, the reasons why these percentages are so high have not been reported. They might be related to the 
characteristics of the residential areas of these municipalities, and to the fact that many people have their second home in these municipalities and may have executed maintenance works in their households during the execution of the WCA (summer). On the other hand, the lowest percentage of BW corresponds to the capital of the region, where almost no small vegetal fractions are thrown away $(0.16 \%)$, and a low proportion of food is wasted (18\%). This value is highly improbable, but since no anomaly has been reported in the sampling, it has been included in the study.

\section{Statistical Modelling (MLRA)}

The relation among the BW generation obtained using WCA, and a selection of variables that have influence on it representing the socio-economic situation of the area, have been considered to execute the MLRA: (i) population density (PD, inh/Km ${ }^{2}$ ), (ii) senior index ( $\mathrm{SN}, \%$ ), (iii) junior index (JN, \%), (iv) retirement index (RI, \%), (v) people working in agriculture and livestock (S1,\%), (vi) people working in the industry (S2,\%) and (vii) people working in the services sector (S3,\%). In Table A1 of the Appendix, the input data of the MLRA are collected: the value of these variables, as well as the BW generation, that correspond to each municipality in 2016.

Given that these variables are expected to have very different relations to BW generation depending on the rurality of the municipalities two equations have been developed: One for urban municipalities and other for rural ones due to the amount of data is not enough to develop one equation per type of municipality.

After different analyses to identify co-linearity problems, and the need of transformation to normal distributions of the variables, different mathematical methods (INTRO, STEPWISE) have been tested. After these analyses, the need to transform the variables into their logarithmic form was identified. In addition, the exclusion of some variables for urban municipalities due to co-linearity problems and the choice to use the method INTRO were made. As a result, the following statistical parameters, for the two MLRA have been obtained (Table 4):

The $\mathrm{R}^{2}$ values obtained for both analyses are upper to 0.8 , which means that the existing correlation among the variables is adequate in both cases, so the two models are well adjusted considering the aim of the study.

Co-linearity problems can be identified through the analysis of the Tolerance, and the Variance Inflation Factor (VIF). Tolerance represents the proportion of the variance of each independent variable that is not explained by the remaining independent variables [23]. For both types of municipalities, none of the Tolerance values are close to zero, which allows to initially reject the existence of colinearity problems among the variables. The VIF, which is the inverse of the Tolerance, must have low values in order to definitely conclude that there is no co-linearity among variables. For urban municipalities, these values are inferior to 5.0, as well as the majority of variables for rural municipalities. Although, VIF values that correspond to Ln PD, Ln SN and Ln S1 for rural municipalities oscillate between 5.0 and 9.0, co-linearity problems are rejected, so no variables have to be excluded from the model.

Using these coefficients, Eqs. 3 and 4 have been developed. According to the equations, in urban municipalities only four variables have influence on BW generation, while in municipalities that tend to rurality are seven the variables with influence.

$L n B W_{U r b a n_{i, j}}=4.628+0.144 * \operatorname{Ln}_{P D_{i, j}}-0.219 * L N_{S 1_{i, j}}-0.876 * \operatorname{Ln}_{S 2_{i, j}}+1.158 * L n_{S 3_{i, j}}$

$L n B W_{\text {Rural }_{i, j}}=0.805+0.613 * L n_{P D_{i, j}}-0.879 * L n_{S N_{i, j}}+0.551 * L n_{J N_{i, j}}+0.413 * L n_{R I_{i, j}}+0.207 * L N_{S 1_{i, j}}-0.027 * L n_{S 2_{i, j}}+0.594 * L n_{S 3_{i, j}}$

Table 4 Coefficients for BW generation estimation

\begin{tabular}{|c|c|c|c|c|c|c|c|c|}
\hline \multirow[t]{2}{*}{ MODEL } & \multicolumn{2}{|c|}{ Coefficients } & \multicolumn{2}{|c|}{ Tolerance } & \multicolumn{2}{|l|}{ VIF } & \multicolumn{2}{|l|}{$\mathrm{R}^{2}$} \\
\hline & Urban & Rural & Urban & Rural & Urban & Rural & Urban & Rural \\
\hline Independent term & 4.628 & 0.805 & - & - & - & - & 0.849 & 0.828 \\
\hline Ln PD & 0.144 & 0.613 & 0.473 & 0.157 & 2.116 & 6.365 & & \\
\hline Ln SN & - & -0.879 & - & 0.111 & - & 9.000 & & \\
\hline Ln JN & - & 0.551 & - & 0.277 & - & 3.614 & & \\
\hline Ln RI & - & 0.413 & - & 0.237 & - & 4.227 & & \\
\hline Ln S1 & -0.219 & 0.207 & 0.494 & 0.189 & 2.025 & 5.287 & & \\
\hline Ln S2 & -0.876 & -0.027 & 0.323 & 0.733 & 3.096 & 1.364 & & \\
\hline Ln S3 & 1.158 & 0.594 & 0.316 & 0.721 & 3.162 & 1.386 & & \\
\hline
\end{tabular}


$L n B W_{C A N T A B R I A}=\sum_{j=4,5}^{9} \operatorname{LnBW}_{\text {Urban }_{i, j}}+\sum_{j=1,2,3}^{93} \operatorname{LnBW}_{\text {Rural }_{i, j}}$

where $\mathrm{i}=$ municipality, $\mathrm{j}=$ rurality category.

If Eqs. 3 and 4 are compared, the number of socioeconomic variables, as well as their influence on BW generation are higher in rural than in urban municipalities. This is because urban municipalities have intrinsic socio-economic characteristics that make them prone to generate wastes of any kind, diminishing the weight of other aspects that may influence BW generation. This is properly reflected in the equations, through the weight of the variable part (socio-economic variables) and the fixed part (independent term). This is represented in Fig. 4, where the weight of the socio-economic variables and the independent term are shown.

According to the model, for rural municipalities, the values of the socio-economic variables affect more the amount of BW generation. The idiosyncrasy of these municipalities is much more varied than in the case of urban ones. This is reflected in the variability of the values of the socioeconomic variables, and therefore in the amount of BW generated.

The population density (PD) has the most positive influence on BW generation. It coincides with the studies of Ghinea et al. [18] and Azadi and Karimi-Jashni [19], that also conclude that population density and working population have a positive influence on MSW and BW generation. On the other hand, the senior index (SN), is the variable with the most negative influence on BW generation level. Older people have another model of consumption and try to make the most of the food leftovers. This agrees with Grazdhani [20] who concluded that population of more than 65 years, has a negative influence on MSW generation.

Other variables with positive influence are junior index $(\mathrm{JN})$, retirement index (RI), people working in agriculture and livestock (S1) and people working in the services sector (S3). Generally, families with young people have a higher

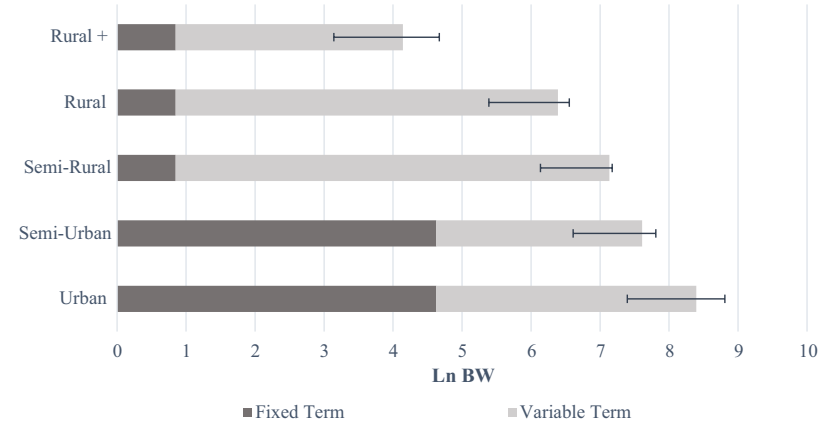

Fig. 4 Influence of the socio-economic variables on BW generation depending on rurality consumption of food per household and therefore of FW. Regarding occupation, different studies conclude that working population has a positive effect on waste generation. However, the type of occupation is not studied in their work [18]. The agriculture and livestock are very representative of rural areas, and a high proportion of population are part of this sector, which can generate vegetal fractions as well as FW. Although the services sector is not as important in rural areas as in urban areas, due to the nature of its activity, it contributes to BW generation.

In Fig. 5, it is graphically shown how the weight of these variables will influence the BW generation for urban and rural municipalities, presenting a mean value that increases as the municipalities are analysed in increasing order of rurality index. (the more urban the municipality is, the greater the generation of BW will be in it).

\section{Biowaste Estimation Using MLRA Models}

The BW generation in Cantabria was estimated using the model equations for the period 2012-2017 (Fig. 6). It varies in this period between 61,800 and 66,900 tons per year, which corresponds to a generation ratio from 106 to $115 \mathrm{~kg} /$ capita/year.

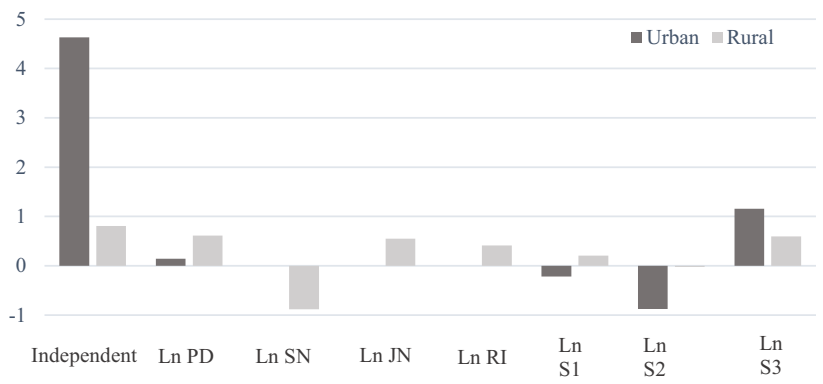

Fig. 5 Influence of the socio-economic variables on BW generation

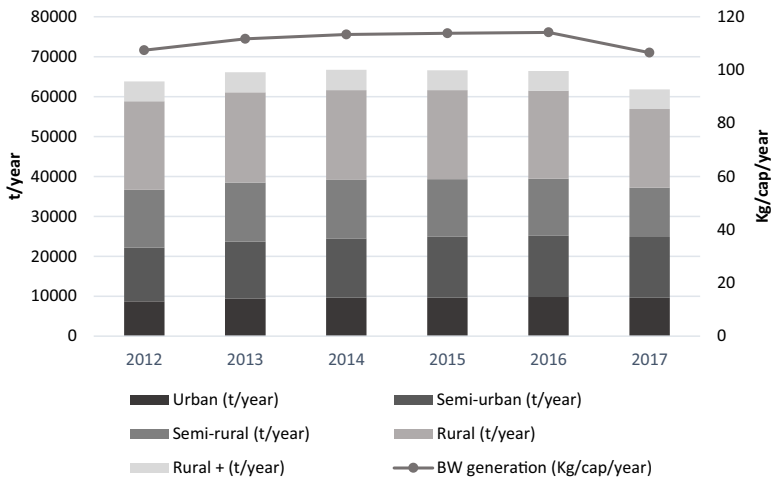

Fig. 6 BW generation in cantabria estimated using MLRA 
These estimated ratios have a similar magnitude to the ones obtained by Quested et al. [33] for United Kingdom, Kranert et al. [34] for Germany, Edjabou et al. [35] for Denmark, and Braütigam et al. [36] for Spain, given that they oscillate between 100 and $118 \mathrm{~kg} /$ capita/year.

Using this method, the lack of homogenesis of the BW generation in the different types of municipalities is clear, as it is shown in Fig. 6. During the studied period, the 37\% of the BW is generated in urban and semi-urban municipalities, while the $63 \%$ is generated in semi-rural, rural and rural ${ }^{+}$municipalities. This means that the $37 \%$ of the total BW is generated by the $56 \%$ of the total population in Cantabria, who are concentrated in the $3 \%$ of the area of the region. Provided that the remaining $63 \%$ of the BW generation is produced in the $97 \%$ of the area, the efforts to introduce the separate collection and management of BW, as well as the assessment of their performance, must not be made only in urban and semi-urban areas, but also in rural and low populated areas.

However, this distribution varies along the years. The trend followed by BW generation in the different municipalities in Cantabria, is associated to the evolution of the most relevant socio-economic variables used in the MLRA. As it is shown in Table A2 in the Appendix, population density has changed differently through the years, depending on the rurality of the municipalities. In urban, semi-urban and rural $^{+}$municipalities, PD has gradually decreased, but with a higher intensity in urban and semiurban municipalities. On the other hand, PD has oscillated in semi-rural and rural municipalities, finishing the studied period with a slight increase in relation to the previous year.

According to the values collected in Table A2 in the Appendix, job market has also suffered variations during the studied period. The evolution of the percentage of people working in the primary sector through the years is quite different depending on the rurality of the municipalities. In urban municipalities, S1 has oscillated during the studied period, ending it with a decrease in relation to the year 2016. In semi-urban, semi-rural and rural municipalities S1 increased during the beginning of the studied period, to decrease gradually till 2017. Only in rural ${ }^{+}$municipalities S1 has increased during the majority of the studied years. However, it decreased in 2017.

The percentage of people working in the industry sector has followed a similar trend in the whole region. During the years 2012-2016, S2 has decreased gradually, except in 2014 in rural municipalities, to finish the studied period with an increase in every type of municipality.

As a consequence, the percentage of people working in the service sector has gradually increased in the five categories of municipalities, during the years 2012-2016 to finish the studied period decreasing in 2017.

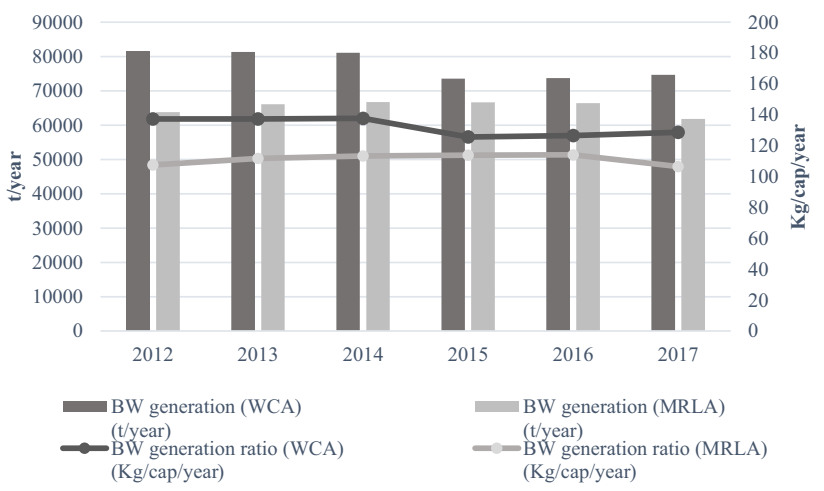

Fig. 7 Comparative BW generation WCA and MRLA

Through the analysis of the trend followed by these variables and its link with the one followed by the distribution of BW, the strong connection between the socio-economic variables of the municipalities and the BW generated in each one of them is proved. Therefore, they have to be considered when decisions related to BW collection and management must be made.

The estimations obtained through the model, are compared to other made using WCA (2016) ratios and MSW collection data of the same period (Fig. 7). These values are collected in Tbale A3 of the Appendix. The estimations have lower values during the whole studied period, with a percentual difference between 9 and $21 \%$.

These differences lie with the fact that the WCA was executed during summer season (2016), when population, tourism and the intensity of the services sector's activity grows exponentially. On the contrary, the statistical data used to make the estimations using MLRA correspond to the whole year, and do not include people from outside the region who have their second home in Cantabria.

It is expected that the values of the BW estimated using the ratio obtained in the WCA will be worse the further away from the year in which it was obtained, since the evolution of the economic crisis of the last decade, as well as the greater awareness of society with FW, have changed the consumption patterns. This is one of the reasons why it is not recommended to use static ratios and it is recommended to use models that allow including socio-economic changes in the estimation of waste generation.

\section{Conclusions}

European countries must develop a new BW management strategy in the coming years due to changes in the regulations. In this sense, it is necessary to be able to quantify the generation of this waste at the municipal level. 
In this paper, a methodology to estimate BW generation at municipal level has been established. The methodology takes into account the characteristics of the region, the MSW management applied, and different socio-economic variables that define the level of rurality of a municipality. A model to estimate the BW generation for each type of municipality (urban or rural) has been developed using MLRA. It has been proved that MRLA is an easy-to-use and accurate enough tool, to model the distribution of BW generation in the region. As input data, results from a WCA and data of socio-economic variables that have demonstrated to influence the generation of waste, have been used.

The number of socio-economic variables, as well as their influence on BW generation are higher in rural than in urban municipalities, given that urban municipalities have intrinsic characteristics that make them prone to generate wastes of any kind, diminishing the weight of other aspects that may influence BW generation. This coincides with the fact that the variable part of the equation is more relevant for rural municipalities than for urban municipalities.

According to the model, the BW generation in Cantabria during the 2012-2017 period varies between 61,800 and 66,900 tons per year, which corresponds to a generation ratio of 106 and $115 \mathrm{~kg} / \mathrm{capita} /$ year. However, as it was expected, the distribution of BW generation is not homogeneous: the $37 \%$ of the BW is generated in urban and semi-urban municipalities, while the $63 \%$ is generated in semi-rural, rural and rural $^{+}$municipalities. Therefore, the efforts to introduce the separate collection and management of BW in the point of production, as well as the assessment of their performance, must not be made only in urban and semi-urban areas, but in rural and low populated areas too.

After comparing the value of BW production obtained using the models, with those obtained using single ratios, differences were found among both values. The evolution of the economic crisis of the last decade, as well as the greater awareness of society with $\mathrm{FW}$, have changed the consumption patterns. This is one of the reasons why it is not recommended to use static ratios and it is recommended to use models that allow including socio-economic changes in the estimation of waste generation.

Supplementary Information The online version contains supplementary material available at https://doi.org/10.1007/s12649-021-01571-2.

Acknowledgements This work has been financially supported by the Government of Cantabria R\&D project entitled "Obtention, treatment and dissemination of data related to production and management of waste, and adjustment of the existing indicators system to the valid waste plan of Cantabria". The public company MARE S.A. has provided the MSW generation data, as well as the WCA characterisations used to develop the statistical modelling.

Funding Open Access funding provided thanks to the CRUE-CSIC agreement with Springer Nature.

Data Availability All data generated or analysed during this study are included in this published article.

\section{Declarations}

Conflict of interest The authors declare there is no conflict of interest.

Open Access This article is licensed under a Creative Commons Attribution 4.0 International License, which permits use, sharing, adaptation, distribution and reproduction in any medium or format, as long as you give appropriate credit to the original author(s) and the source, provide a link to the Creative Commons licence, and indicate if changes were made. The images or other third party material in this article are included in the article's Creative Commons licence, unless indicated otherwise in a credit line to the material. If material is not included in the article's Creative Commons licence and your intended use is not permitted by statutory regulation or exceeds the permitted use, you will need to obtain permission directly from the copyright holder. To view a copy of this licence, visit http://creativecommons.org/licenses/by/4.0/.

\section{References}

1. Parliament, E.: Council: directive 2008/98/EC of the european parliament and of the council of 19 november 2008 on waste and repealing certain directives. Off. J. Eur. Union L312, 3-30 (2008)

2. Parliament, E.: Council: directive 2018/851 of the european parliament and of the council of 30 may 2018 amending directive 2008/98/CE on waste. Off. J. Eur. Union L150, 109-140 (2018)

3. Spanish government, ministry for the ecological transition and the demographic challenge: what is biowaste?. MITECO. (2020). https://www.miteco.gob.es/es/calidad-y-evaluacion-ambiental/ temas/prevencion-y-gestion-residuos/flujos/biorresiduos/Defau 1t.aspx. Accessed 12 Sep 2019.

4. Oviedo-Ocaña, E.R., Domínguez, I., Komilis, D., Sánchez, A.: Co-composting of Green waste mixed with unprocessed and processed food waste: influence on the composting process and product quality. Waste. Biomass. Valor. 10, 63-74 (2019). https:// doi.org/10.1007/s12649-017-0047-2

5. BIO intelligence service: preparatory study on food waste across EU 27 October 2010. European commission. (2010). https://ec. europa.eu/environment/eussd/pdf/bio_foodwaste_report.pdf. Accessed 23 Feb 2020

6. Panaretou, V., Malamis, D., Papadaskalopoulou, C., Sotiropoulos, A., Valta, K., Plevri, A., Margaritis, M., Moustakas, K., Loizidou, M.: Implementation and evaluation of an integrated management scheme for MSW in selected communities in tinos Island. Greece. Waste. Biomass. Valor. 8, 1597-1616 (2017). https://doi.org/10. 1007/s12649-016-9632-z

7. Prieto-Lara, E., Ocaña-Riola, R.: Updating rurality index for small areas in Spain. Soc. Indic. Res. 95, 267-280 (2010). https://doi. org/10.1007/s11205-009-9459-0

8. Sancho Comíns, J., Reinoso Moreno, D.: La delimitación del ámbito rural: una cuestión clave en los programas de desarrollo rural. Estud. Geogr. 73, 599-624 (2012). https://doi.org/10.3989/ estgeogr.201221 
9. United Nations: principles and recommendations for population and housing censuses. Economical and social Affairs, New York (1998).

10. Organisation for Economic Co-operation and Development: Creating rural indicators for shaping territorial policy. OCDE Publications and Information Centre, Paris (1994)

11. Spanish Government, Ministry of Agriculture, Fishing and Feeding: El libro blanco de la agricultura y el Desarrollo rural/The white book of agricultural and rural development. Ministry of Agriculture, Fishing and Feeding, Madrid (2003)

12. López-Ratón, M., Santiago Pérez, I.: Construcción de un índice de ruralidad y clasificación de los municipios gallegos/Construction of a rurality index and classification of municipalities of Galicia. Extended paper in: I Congresso de Estatística e Investigação Operacional da Galiza e Norte de Portugal. (2005). https://www. ige.eu/2Festatico/2Fgrupo_de_traballo_urbanizacion\%2FRural. doc\&usg=AOvVaw2ItwKpYs-tNpoiW8rqFfvi. Accessed 25 May 2008

13. Ocaña-Riola, R., Sánchez-Cantalejo, C.: Rurality index for small areas in Spain. Soc. Indic. Res. 73, 247-266 (2005). https://doi. org/10.1007/s11205-004-0987-3

14. Xue, L., Liu, G., Parfitt, J., Liu, X., Van Herpen, E., Stenmarck, Å., O'Connor, C., Östergren, K., Cheng, S.: Missing food, missing data? A critical review of global food losses and food waste data. Environ. Sci. Technol. 51, 6618-6633 (2017). https://doi.org/10. 1021/acs.est.7b00401

15. WRAP: Household food and drink waste in the UK. WRAP, Banbury. (2009). https://www.wrap.org.uk/sites/files/wrap/House hold_food_and_drink_waste_in_the_UK_-_report.pdf. Accessed 15 February 2020

16. Malamis, D., Moustakas, K., Bourka, A., Valta, K., Papadaskalopoulou, C., Panaretou, V., Skiadi, O., Sotiropoulos, A.: Compositional analysis of biowaste from study sites in greek municipalities. Waste. Biomass. Valor. 6, 637-646 (2015). https://doi.org/ 10.1007/s12649-015-9406-Z

17. Tostivint, C., de Veron, S., Jan, O., Lanctuit, H., Hutton, Z.V., Loubière, M.: Measuring food waste in a dairy supply chain in Pakistan. J. Clean. Prod. 145, 221-231 (2017). https://doi.org/10. 1016/j.jclepro.2016.12.081

18. Ghinea, C., Drăgoi, E.N., Comăniţă, E.D., Gavrilescu, M., Câmpean, T., Curteanu, S., Gavrilescu, M.: Forecasting municipal solid waste generation using prognostic tools and regression analysis. J. Environ. Manage. 182, 80-93 (2016). https://doi.org/ 10.1016/j.jenvman.2016.07.026

19. Azadi, S., Karimi-Jashni, A.: Verifying the performance of artificial neural network and multiple linear regression in predicting the mean seasonal municipal solid waste generation rate: A case study of fars province. Iran. Waste Manag. 48, 14-23 (2016). https://doi. org/10.1016/j.wasman.2015.09.034

20. Grazhdani, D.: Assessing the variables affecting on the rate of solid waste generation and recycling: an empirical analysis in Prespa Park. Waste Manag. 48, 3-13 (2016). https://doi.org/10. 1016/j.wasman.2015.09.028

21. Owusu-sekyere, E., Harris, E.: Forecasting and planning for solid waste generation in the kumasi metropolitan area of Ghana: an ARIMA time series approach. Int. J. Sci. 2, 69-83 (2013)

22. Mwenda, A., Kuznetsov, D., Mirau, S.: Time series forecasting of solid waste generation in Arusha city - Tanzania. Math. Theory Model. 4, 29-39 (2014)
23. Guisande González, C., Vaamonde Liste, A., Barreiro Felpeto, A.: Tratamiento de datos con R, STATISTICA y SPSS/Data treatment with R, STATISTICA and SPSS. Ediciones DíazdeSantos (2013)

24. Statistics Office of Cantabria (ICANE): Cantabria en cifras 2019/ Cantabria in figures 2019. (2020). https://www.icane.es/c/docum ent_library/get_file?uuid=f6d323a9-7fb6-4c6a-90cb-239458c7a2 7b\&groupId=10138. Accessed 17 January 2020

25. Villaverde Castro, J., Agudo San Emeterio, A., Maza Fernández, A.: El desarrollo económico de Cantabria: Análisis e instrumentos/The economic development of Cantabria: Analysis and tools. SODERCAN (2017)

26. El Diario Montañés. De ciudades fantasma a superpobladas. (2018). https://www.eldiariomontanes.es/cantabria/ciudadesfantasma-superpobladas-20180902213359-ntvo.html. Accessed 15 July 2021

27. BOE: Spanish lay $22 / 2011$, of 28 July on wastes and contaminated soils. Head of State (2011)

28. BOC: Decree 14/2017, of 23 March, which approves the Waste Plan of Cantabria 2017-2023. Government of Cantabria. 63 (2017)

29. Quintá, F.X.A., Arce, X.C.M.: Reflexiones acerca de la delimitación y definición del medio rural. Diseño de un índice de ruralidad para Galicia. Finisterra. 52, 85-101 (2017). https://doi.org/10. 18055/Finis9955

30. Lasarte-López, J., Rodero-Cosano, M.L., Salinas Pérez, J.A.: La medición de la ruralidad y sus dimensiones en Andalucía a través de un modelo de indicadores sociales. Extended paper in: International Conference on Regional Science (2016)

31. Castañeda, M.B., Cabrera, A.F., Navarro, Y., de Vries, W.: Procesamiento de datos y análisis estadísticos utilizando SPSS. Editora Universitária da PUCRS, Porto Alegre (2010)

32. Ministry of Agriculture, Feeding and Environment: Gestión de biorresiduos de competencia municipal: Guía para la implantación de la recogida separada y tratamiento de la fracción orgánica/ Guidelines for the implementation of biowaste separate collection and biowaste management. Ministry of Agriculture, Feeding and Environment, Madrid (2013)

33. Quested, T., Ingle, R., Parry, A.: Household food and drink waste in the United Kingdom 2012. WRAP, Banbury (2013). https:// wrap.org.uk/sites/files/wrap/hhfdw-2012-main.pdf.pdf. Accessed $15 \mathrm{Feb} 2020$

34. Kranert, M., Hafner, G., Barabosz, J., Schneider, F., Lebersorger, S., Scherhaufer, S., Schuller, H., Leverenz, D.: Determination of discarded food and proposals for a minimization of food wastage in Germany. Water Quality and Solid Waste Management University Stuttgart, Institute for Sanitary Engineering (2012)

35. Edjabou, M.E., Petersen, C., Scheutz, C., Astrup, T.F.: Food waste from Danish households: generation and composition. Waste Manag. 52, 256-268 (2016). https://doi.org/10.1016/j.wasman. 2016.03.032

36. Bräutigam, K.R., Jörissen, J., Priefer, C.: The extent of food waste generation across EU-27: different calculation methods and the reliability of their results. Waste Manag. Res. 32, 683-694 (2014). https://doi.org/10.1177/0734242X14545374

Publisher's Note Springer Nature remains neutral with regard to jurisdictional claims in published maps and institutional affiliations. 


\section{Authors and Affiliations}

M. Baquero ${ }^{1} \cdot$ E. Cifrian ${ }^{1}$ (1) $\cdot$ L. Pérez-Gandarillas ${ }^{1} \cdot A$. Andrés $^{1}$

$\triangle$ E. Cifrian

cifriane@unican.es

1 Green Engineering \& Resources Research Group (GER),

Department of Chemistry and Process \& Resource
Engineering, ETSIIT, University of Cantabria, Avenida los Castros s/n. 39005, Santander, Cantabria, Spain 